\title{
Perceptual Experience and Auditory Inclination of Music According to the Sexuality
}

\author{
Shveata Misra, Ina Shastri \\ Department of Music, Banasthali University, Rajasthan, India \\ Email address: \\ shveata@yahoo.com (S. Misra), ina_shastri@yahoo.com (I. Shastri)
}

\section{To cite this article:}

Shveata Misra, Ina Shastri. Perceptual Experience and Auditory Inclination of Music According to the Sexuality. Psychology and Behavioral Sciences. Vol. 5, No. 1, 2016, pp. 7-11. doi: 10.11648/j.pbs.20160501.12

\begin{abstract}
Music has evolved as a powerful medium in past few years. Not just to communicate your thoughts and feelings but also with many aspects that could be termed as mysterious nature of music unrevealed. In today's mundane life the impression of music on one's personality behaviour is so impactful that this perceptual cognitive adherence of music could be seen and observed clearly the way one behave and react with music. It has more to do with the auditory inclination of every individual, be like romantic, sad, and pop, jazz opera and many more. This proposed research paper would reveal how auditory inclination is related to personality and individual inclination of music according to sexuality. The result was, was an eye opener to the fact that music is just not what one listen but it has main relation to the one's personality as well. Each individual that listen to music is the reflection of their personality unlike its dependency on sexuality aspect.
\end{abstract}

Keywords: Auditory, Female, Gender, Male, Music, Perceptual, Personality

\section{Introduction}

To outline the research I took up for my Ph. D was to see how auditory inclination of music impacts the personality of every individual in all age groups i. e. from adolescents to older age people. As I proceed further I found that one who listen's music of their choice is actually related to the personality they possess. The auditory inclination is directly related to the personality one has and that what even reflect in their perceptual experience. This mundane life, music is the primary source to relax, to refresh and to rejuvenate from within.

There are mainly 23 genres in music from blue, pop, jazz, opera, to romantic, alternatives, funk etc. To point the individuals' music inclination I divided these genres into 4 groups as:

1. Upbeat:

2. Energetic,

3. Rebellious,

4. Complex.

To find out the individuals amount of importance given to music I prepared a musical test which is as follows:
Table 1. Music Inclination.

\begin{tabular}{lllll}
\hline Classical & 1 & 2 & 3 & 4 \\
Bollywood & 3 & 2 & 3 & 4 \\
Blues & 1 & 2 & 3 & 4 \\
Funk & 1 & 2 & 3 & 4 \\
Pop & 1 & 2 & 3 & 4 \\
Jaaz & 1 & 2 & 3 & 4 \\
Alternatives & 1 & 2 & 3 & 4 \\
Ghazals & 1 & 2 & 3 & 4 \\
Folk & 1 & 2 & 3 & 4 \\
Gospel & 1 & 2 & 3 & 4 \\
Instrumental & 1 & 2 & 3 & 4 \\
Heavy Metal & 1 & 2 & 3 & 4 \\
New age & 1 & 2 & 3 & 4 \\
Oldies & 1 & 2 & 3 & 4 \\
Bluegrass & 1 & 2 & 3 & 4 \\
New Age & 1 & 2 & 3 & 4 \\
Rap/Hip-hop & 1 & 2 & 3 & 4 \\
Religious & 1 & 2 & 3 & 4 \\
Dance & 1 & 2 & 3 & 4 \\
Country & 1 & 2 & 3 & 4 \\
Sound Track & 1 & 2 & 3 & 4 \\
Light Music & 1 & 2 & 3 & 4 \\
Rock & 1 & 2 & 3 & 4 \\
\hline
\end{tabular}

1-Very Important, 2-Important, 3-Somewhat Important, 4-Neutral, 5Somewhat Unimportant, 6-Unimportant, 7-Very Unimportant. 
Table 2. Your Life and Activities-How Important is.

\begin{tabular}{lllll}
\hline Music & 1 & 2 & 3 & 4 \\
Job & 1 & 2 & 3 & 4 \\
T.V & 1 & 2 & 3 & 4 \\
Books \& Magzines & 1 & 2 & 3 & 4 \\
Movies & 1 & 2 & 3 & 4 \\
Hobbies & 1 & 2 & 3 & 4 \\
\hline
\end{tabular}

Table 3. Music as companion For Situations.

\begin{tabular}{lllll}
\hline Alone & 1 & 2 & 3 & 4 \\
In Morning & 1 & 2 & 3 & 4 \\
Studying & 1 & 2 & 3 & 4 \\
Driving & 1 & 2 & 3 & 4 \\
Working & 1 & 2 & 3 & 4 \\
With Friends & 1 & 2 & 3 & 4 \\
While exercising & 1 & 2 & 3 & 4 \\
Washroom & 1 & 2 & 3 & 4 \\
While going to sleep & 1 & 2 & 3 & 4 \\
\hline
\end{tabular}

Table 4. Feeling induce Music - The Aesthetically attached You.

\begin{tabular}{lllll}
\hline Love : Sringar & 1 & 2 & 3 & 4 \\
Mirth : Hasya & 1 & 2 & 3 & 4 \\
Fury : Raudr & 1 & 2 & 3 & 4 \\
Compassion: Karun & 1 & 2 & 3 & 4 \\
Disgust : Bhibhats & 1 & 2 & 3 & 4 \\
Horror: Bhayanak & 1 & 2 & 3 & 4 \\
Heroic Mood: Vir & 1 & 2 & 3 & 4 \\
Amazement : Adhbhut & 1 & 2 & 3 & 4 \\
Peace: Shant & 1 & 2 & 3 & 4 \\
Parental Love: Vatslya & 1 & 2 & 3 & 4 \\
Devotion : Bhkati & 1 & 2 & 3 & 4 \\
\hline
\end{tabular}

To judge the personality I took the personality test based on Extraversion, Openness, conscientiousness, Neuroticism and Agreeableness followed by a questionnaire to have the personality traits of each. All the questionnaires and test were psychometrically approved.

\section{Objective}

1. To find that there is or there isn't any significant association in gender and personality for all music types and for all age groups.

2. To find that does liking for any type of music will have same type of effect on personality irrespective of gender

3. To compare average score obtained by rural and urban persons according to their personality traits and music inclinations for various age groups.

Method:

Using the purposive sampling procedure, the total number of sample taken for the age group $13-19$ years, $20-40$ years and $40-75+$ years were 1000. $13-19$ years of youth were from the classes 8 th to graduation level. It includes the students from the schools and universities of Lucknow, Kanpur and Rajasthan. $20-40$ years of people were from the post graduation level including the working people from the field of engineering, doctors, bankers etc. 40 - $75+$ years of people were engaged into different jobs, business, few were retired people and some were from the old age homes as well.

\section{Descriptive Analysis}

- First analysis is on females with the age group of 13 19 years including the 5 personality traits and four music types. Amongst the 500 females 461 answered the questionnaires, between the age group of $13-19$ years. So Individual analysis of each gender in Adolescents (13-19 years) are as follows:

\section{A. FEMALE:}

Females have answered the questionnaire related to personality and music type interest. Based on those questionnaires a graphical presentation has been done that will individually show personality and their music interest accordingly:

Hol - There is an association between the music inclination and personality of females.

$H 1$ - There is no association between the music inclination and personality of females.

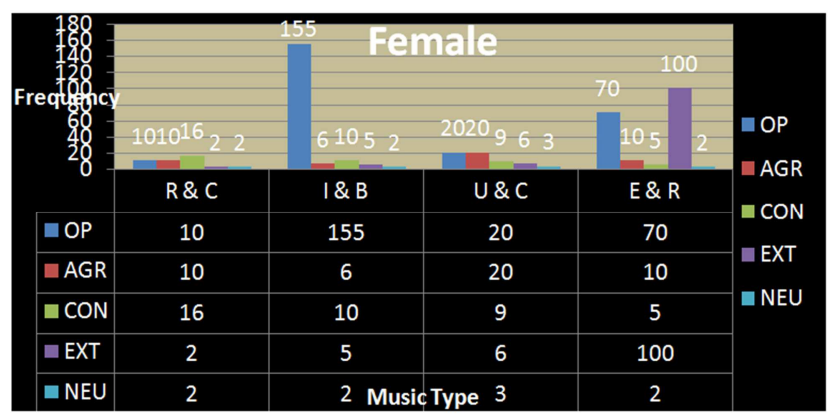

(A)

Fig. 1. Gender Based Analysis (Female 13-19 years)(A).

As we can see in the above graph the most highlighted personality trait and music type is that of Openness and Extraversion with inclination towards two music type i. e. Intense and Rebellious and Energetic and Rhythmic Music types respectively.

According to the individual analysis of females, it shows that the number of females who are of Openness personality have inclination towards Intense and rebellious music type.

Now for the significant association in inclination towards music and personality of females we applied $\mathrm{X}^{2}-$ Test to see the association at $5 \%$ level of significance. To test the hypothesis between music inclination and personality of females, the value of $\mathrm{X}^{2}$ obtained is reported below:

$\mathrm{X}^{2}-$ value $=2.850 \mathrm{E} 2$ and corresponding $\mathrm{p}-$ value $=.000$

Since the $\mathrm{p}$ - value is less than .05; therefore it implies that there is a significant association in inclination towards music and personality of females between the age group of $13-19$ years.

Second analysis is on males between the age group of $13-$ 19 years including the 5 personality traits and four music types. Amongst the 500 males 481 answered the questionnaires. So Individual analysis of the following gender in Adolescents (13-19 years) is as follows:

B. MALE:

Males have answered the questionnaire related to 
personality and music type interest. Based on those questionnaires a graphical presentation has been done that will individually show personality and their music interest accordingly:

Ho2 - There is an association between the music inclination and personality of males.

$H 2$ - There is no association between the music inclination and personality of males.

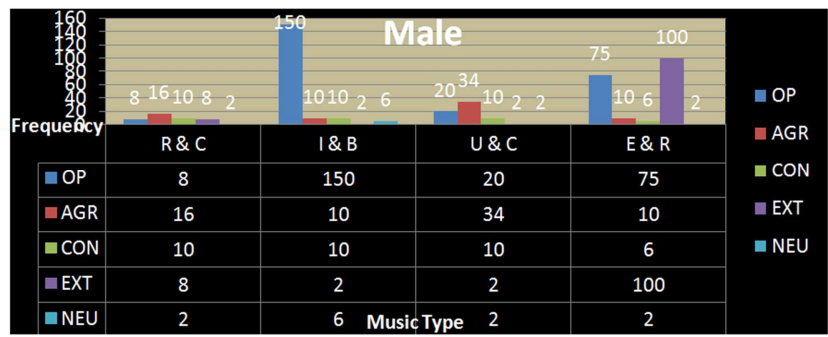

(A)

Fig. 2. Gender Based Analysis (Male 13-19 years) (A).

As we can see in the above graph the most highlighted personality trait and music type is that of Openness and Extraversion with inclination towards two music type which is Intense and Rebellious and Energetic and Rhythmic Music types respectively.

According to the individual analysis of males, it shows that the number of males who are of Openness personality have inclination towards Intense and rebellious music ty.

Now for the significant association in inclination towards music and personality of males we applied $\mathrm{X}^{2}-$ Test to see the association at $5 \%$ level of significance. To test the hypothesis between music inclination and personality of males, the value of $\mathrm{X}^{2}$ obtained is reported below:

$\mathrm{X}^{2}-$ value $=2.982 \mathrm{E} 2$ and corresponding $\mathrm{p}-$ value $=.00$

Since the $p-$ value is $<.05$; therefore it implies that there is a significant association in inclination towards music and personality of males lying in the age group of $13-19$ years.

\subsection{Conclusion}

Interest of music types highly depends on the personality of person, which means; knowing the personality trait of one, we can easily identify his/her music inclination or vice versa.

According to the above analysis it is very much clear that males and females between the age group of 13 to 19 years, with personality trait of Openness to new experience are observed and found to have inclination towards Intense and Rebellious music types.

A. FEMALE: $20-40$ years.

Females have answered the questionnaire related to personality and music type interest. Based on those questionnaires a graphical presentation has been done that will individually show personality and their music interest accordingly:

Hol - There is an association between the music inclination and personality of females.
$H 1$ - There is no association between the music inclination and personality of females.

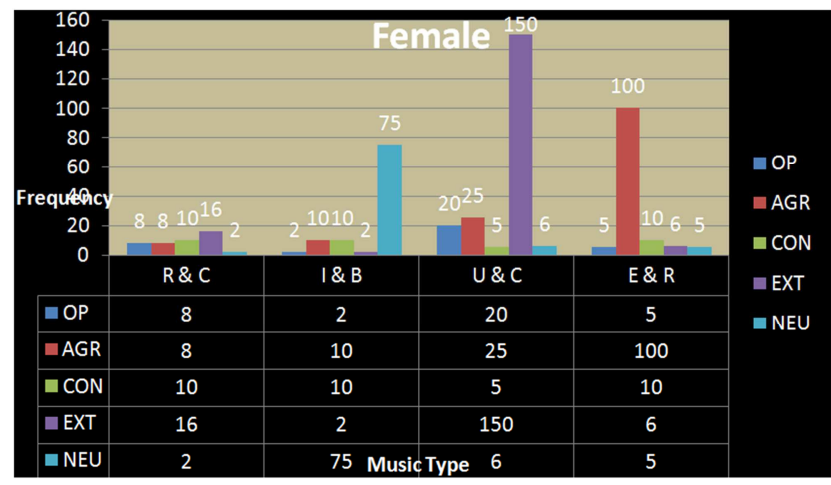

(A)

Fig. 3. Gender Based Analysis (Female 20-40 years) (A).

As we can see in the above graph the most highlighted personality trait and music types are Extraversion and Agreeableness with inclination towards Upbeat and Conventional and Energetic and Rhythmic Music types respectively.

According to the individual analysis of females, it shows that the number of females who are of Extraversion personality have inclination towards Upbeat and Conventional music type.

Now for the significant association in inclination towards music and personality of females we applied $\mathrm{X}^{2}-$ Test to see the association at $5 \%$ level of significance. To test the hypothesis between music inclination and personality of females, the value of $\mathrm{X}^{2}$ obtained is reported below:

$\mathrm{X}^{2}-$ value $=5.373 \mathrm{E} 2$ and corresponding $\mathrm{p}-$ value $=.000$

Since the $p-$ value is $<.05$; therefore it implies that there is a significant association in inclination towards music and personality of females between the age group of $20-40$ years.

- Second analysis is on males with the age group of $20-$ 40 years including the 5 personality traits and four music types. Amongst the 500 males 481 answered the questionnaires. So Individual analysis of the following gender in Adolescents (20-40 years) is as follows:

B. MALE:

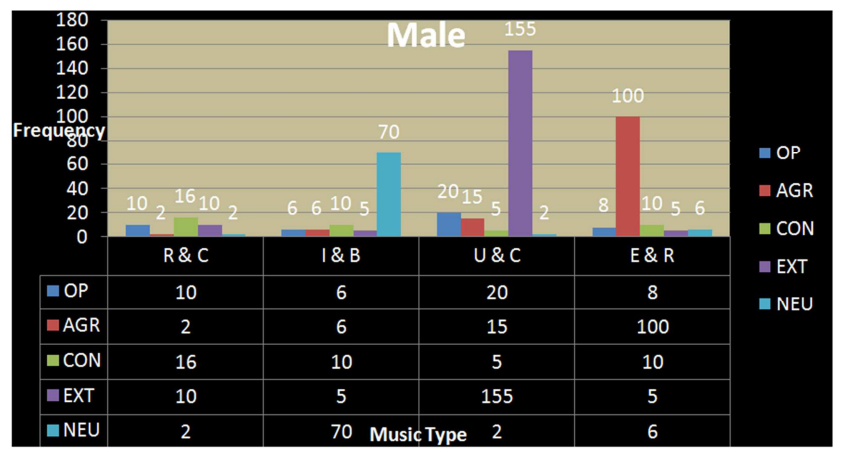

(A)

Fig. 4. Gender Based Analysis (Male 20-40years). 
Males have answered the questionnaire related to personality and music type interest. Based on those questionnaires a graphical presentation has been done that will individually showing personality and their music interest accordingly.

Ho2 - There is an association between the music inclination and personality of males.

$H 2$ - There is no association between the music inclination and personality of males.

As we can see in the above graph the most highlighted personality trait and music types are Extraversion and Agreeableness with inclination towards Upbeat and Conventional and Energetic and Rhythmic Music types respectively.

According to the individual analysis of males, it shows that the number of males who are of Extraversion personality have inclination towards Upbeat and Conventional music type.

Now for the significant association in inclination towards music and personality of females we applied $\mathrm{X}^{2}-$ Test to see the association at $5 \%$ level of significance. To test the hypothesis between music inclination and personality of males, the value of $\mathrm{X}^{2}$ obtained is reported below:

$\mathrm{X}^{2}-$ value $=6.109 \mathrm{E} 2$ and corresponding $\mathrm{p}-$ value $=.000$

Since the $\mathrm{p}-$ value is $<.05$; therefore it implies that there is a significant association in inclination towards music and personality of females lying in the age group of $20-40$ years.

\subsection{Conclusion}

According to the above analysis it is quite evident and clear that the males and females between the age groups of 20 - 40years with personality traits of Extraversion is found and observed to have inclination towards Upbeat and Conventional music type.

FEMALE: $40+-75+$ years.

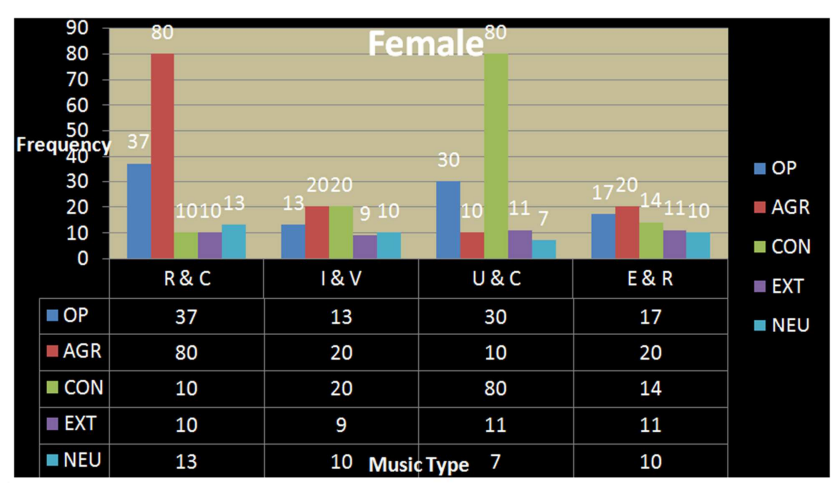

(A)

Fig. 5. Gender Based Analysis (Female 40-75+ years) (A).

Females have answered the questionnaire related to personality and music type interest. Based on those questionnaires a graphical presentation has been done that will individually show personality and their music interest accordingly:

Hol - There is an association between the music inclination and personality of females.

$H 1$ - There is no association between the music inclination and personality of females.

According to the above graph Agreeableness and Conscientiousness personality trait under the age group of 40 $+-75+$ years have equal number of females with their inclination towards Reflection and Complex and Upbeat and Conventional music types respectively.

Now for the significant association in inclination towards music and personality of females we applied $\mathrm{X}^{2}-$ Test to see the association at $5 \%$ level of significance. To test the hypothesis between music inclination and personality of females, the value of $\mathrm{X}^{2}$ obtained is reported below:

$\mathrm{X}^{2}-$ value $=1.317 \mathrm{E} 2$ and corresponding $\mathrm{p}-$ value $=.000$

Since the $\mathrm{p}-$ value is $<.05$; therefore it implies that there is a significant association in inclination towards music and personality of females lying in the age group of $40+-75+$ years.

- Second analysis is on males with the age group of $40+-$ $75+$ years including the 5 personality traits and four music types. Amongst the 500 males 468 answered the questionnaires that were between the age group of $40+$ $-75+$ years. So Individual analysis of each gender in Adulthood and Senior adulthood ( 40+ - 75+ years) are as follows:

A. MALE:

Males have answered the questionnaire related to personality and music type interest. Based on those questionnaires a graphical presentation has been done that will individually show personality and their music interest accordingly:

Ho2 - There is an association between the music inclination and personality of males.

$H 2$ - There is no association between the music inclination and personality of males.

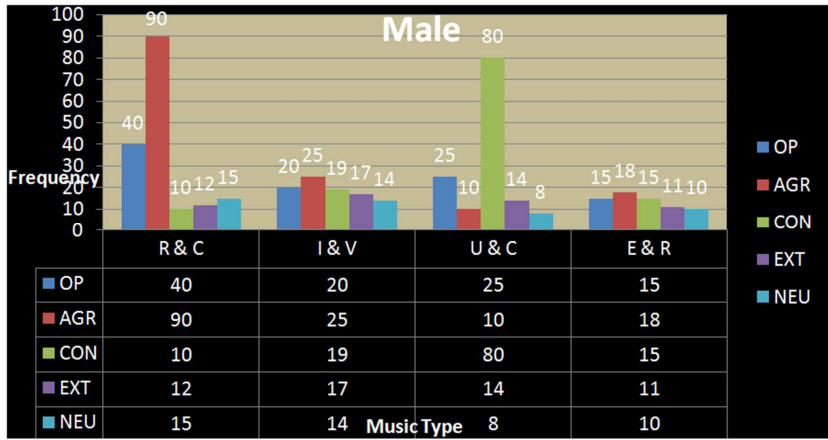

(A)

Fig. 6. Gender Based Analysis (Male 40-75+ years) (A).

According to the above graph it is very clearly evident that Agreeableness and Conscientiousness personality trait under the age group of $40-75+$ years are on the higher side. Though amongst them Agreeableness is having higher number of males with the inclination towards Reflection and Complex music type.

According to the individual analysis of males, it shows that 
the number of males who are of Agreeableness personality have inclination towards Reflection and Complex music type.

Now for the significant association in inclination towards music and personality of males we applied $\mathrm{X}^{2}-$ Test to see the association at 5\% level of significance. To test the hypothesis between music inclination and personality of males, the value of $\mathrm{X}^{2}$ obtained is reported below:

$\mathrm{X}^{2}-$ value $=1.509 \mathrm{E} 2$ and corresponding $\mathrm{p}-$ value $=.000$

Since the $\mathrm{p}-$ value is $<.05$; therefore it which implies that there is a significant association in inclination towards music and personality of males lying in the age group of $40+-75+$ years.

\subsection{Conclusion}

According to the above analysis of males and females in relation with different music types it is found that both males and females between the age group of $40+-75+$ years are found to have Agreeableness personality trait with the inclination towards Reflex and Complex music type. Though, it is also observed that in females same ratio is even found in Consciousness personality trait with inclination towards Upbeat and Conventional music type.

\section{General Conclusion}

From the $\mathrm{x}^{2}$ - values it can be concluded that, there is a significant association in inclination towards music and personality of persons of all age groups which means that the person with different personality have different types of music inclination, it has nothing to do with being male or female.

Interest of music types highly depends on the personality of persons, which means; knowing the personality trait of one, we can easily judge his/her music inclination and vice versa. The perceptual experience $=$ auditory inclination of music is $=$ to the personality one adheres $\neq$ one being of any sexuality.

\section{References}

[1] Adorno, T. W. Frenkel - Brunswik, E., Levinson, D. J., \& Sansford, R. N. (1950). The Authoritarian Personality. New York, NY.

[2] Allport, G. W. (1937). Personaity: A psychological interpretation. New York: Holt, Rinehart \& Winston.

[3] Allport, G. W. (1936). Trait names: A psycho lexical study. Psychological Monographs 47: 211.

[4] Atkinson, Rita, L.; Richard C. Atkinson; Edward E. Smith; Daryl J. Bem; Susan Nolenhoeksema. (2000). Hilgard's Introduction to Psychology (13 ed.). Orlando, Florida: Harcourt College, Publishers, p. 437.

[5] Cacioppo, J. T., \& Petty, R. E. (1982). The need for cognition. Journal of Personality and Social Psychology, p. 42.

[6] Cameron. N. Personality development and Psychopathology, p. $376-377$.

[7] Cattell, H. E. P, and Mead, A. D. (2007). The 16 Personality Factor Questionnaires (16PF). In G. J.

[8] Boyle, G. Matthews, and D. H. Saklofske (Eds.), Handbook of personality theory and testing: Vol. 2: Personality measurement and assessment. London: Sage.

[9] Cattell, R. B. (1990). Advances in Cattellian personality theory. In L. A. Pervin (Ed.), Handbook of personality: Theory and research (pp. 101-110). New York, NY: Guilford Press. 